anales de psicología / annals of psychology

2020, vol. 36, $\mathrm{n}^{\circ} 2$ (may), 340-347

https://doi.org/10.6018/analesps.349561
(C) Copyright 2020: Editum. Servicio de Publicaciones de la Universidad de Murcia. Murcia (Spain) ISSN print edition: 0212-9728. ISSN online edition (http://revistas.um.es/analesps): 1695-2294. Online edition License Creative Commons 4.0: BY-SA

\title{
Basic psychological needs and subjective well-being in Portuguese older people
}

\author{
Nuno Couto ${ }^{1,4}$, Raul Antunes ${ }^{1,3,5}$, Diogo Monteiro ${ }^{1,4}$, João Moutão ${ }^{1,4}$, Daniel A. Marinho ${ }^{2,4}$, and Luís Cid , $^{1,4}$ \\ 1 Sports Science School of Rio Maior (ESDRM), Polytechnic Institute of Santarém (Portugal). \\ 2 University of Beira Interior (UBI) (Portugal). \\ 3 School of Education and Social Sciences (ESECS), Polytechnic of Leiria (Portugal). \\ 4 Research Center in Sports Sciences, Health Sciences and Human Development (CIDESD) (Portugal). \\ 5 Life Quality Research Center (CIEQV) (Portugal).
}

Título: Necesidades psicológicas básicas y bienestar subjetivo en personas mayores portuguesas.

Resumen: El objetivo de este estudio es la validación de la versión en portugués de la Escala General de Satisfacción de Necesidades Básicas (BNSG-S) en una muestra de personas mayores portuguesas, y analizar mediante el modelo de ecuaciones estructurales, el efecto de la percepción global de los ancianos portugueses sobre la satisfacción de las necesidades psicológicas básicas en el bienestar subjetivo. En este estudio se emplearon dos muestras de ancianos portugueses de entre 60 y 90 años de edad. Los resultados revelan que solo el Modelo 3 del BNSG-S (tres factores, 11 ítems) mostró buenos resultados de ajuste a los datos $\left(\chi^{2}=103.16, \mathrm{df}=41\right.$ $\mathrm{SRMR}=.05, \mathrm{TLI}=.90, \mathrm{CFI}=.93, \mathrm{RMSEA}=.07,90 \% \mathrm{CI}=.05-.08) . \mathrm{En}$ la segunda parte del estudio verificamos que la satisfacción de las necesidades psicológicas básicas tiene un efecto positivo en el bienestar subjetivo en los ancianos portugueses.

En presencia de esta evidencia, llegamos a la conclusión de que la versión portuguesa del BNSG-S puede utilizarse como un medio para evaluar la satisfacción de las necesidades psicológicas básicas de la población de mayor edad y su satisfacción tiene un efecto positivo sobre el bienestar subjetivo en la población portuguesa de más edad.

Palabras clave: necesidades psicológicas básicas; bienestar subjetivo; análisis factorial confirmatorio; adultos mayores.
Abstract: The aim of this study is the validation of the Portuguese version of the Basic Need Satisfaction General Scale (BNSG-S) in a sample of Portuguese elderly, and analyze through a structural equations model the effect of the Portuguese elderly individuals' global perception about the satisfaction of basic psychological needs on subjective well-being. Two samples of Portuguese elderly people aged between 60 and 90 years old were considered in this study. Results revealed that they Model 3 of the BNSG-S (three factors, 11 items) adjusted to the data a $\left(\chi^{2}=103.16\right.$, $\mathrm{df}=$ $41, \mathrm{SRMR}=.05, \mathrm{TLI}=.90, \mathrm{CFI}=.93, \mathrm{RMSEA}=.07,90 \% \mathrm{CI}=.05-.08)$. Additionally, structural model analysis, showed a positive and significant effect between satisfaction of basic psychological needs and subjective well-being.

In sum we concluded that the Portuguese version of the BNSG-S can be used as a means to evaluate the satisfaction of the basic psychological needs of the older population and, their satisfaction, has a positive effect on subjective well-being in the Portuguese older population.

Keywords: basic psychological needs; subjective well-being; confirmatory factorial analysis; older population.

\section{Introduction}

The subject's motivation is directly related to factors of social involvement because the influence of these factors is mediated by the fulfilment of all three basic psychological needs (BPN) (Deci \& Ryan, 2008). Ryan and Deci (2007) stated that autonomy (i.e., the subject's ability to regulate his or her own actions), competence (i.e., the subject's efficiency in interaction with the environment), and relatedness (i.e., the subject's ability to search for and develop connections and interpersonal relationships) determine the regulation of the subject's behaviour, it is also an essential condition for social development and well-being (Ryan \& Deci, 2000a, 2002), and the subject is constantly active in the search for satisfaction (Ryan \& Deci, 2000b).

Deci and Ryan's (2000) investigation showed that the higher one's perception is of his/her BPN satisfaction, the more self-determined (more autonomous) is behaviour, which is intimately related with well-being. On the other hand, the lower the BPN satisfaction is, the less self-

* Correspondence address [Dirección para correspondencia]:

Nuno Rafael Pedro do Couto. Escola Superior de Desporto de Rio Maior Instituto Politécnico de Santarém. Av. Dr. Mário Soares 2040-413, Rio Maior (Portugal). E-mail: ncouto@esdrm.ipsantarem.pt

(Article received: 16-11-2018; revised: 5-11-2019; accepted: 7-1-2020) determined (more controlled) is behaviour, which predicts lower levels of well-being (Deci, Koestner, \& Ryan, 1999).

Subjective well-being for the elderly population is considered essential because there is evidence that their high perception is associated with health improvement and longevity (Diener \& Chan, 2011). In general, subjective wellbeing is considered as a cognitive assessment (i.e., life satisfaction) and affective (i.e., positive and negative affect) that people make about their lives (Diener, Suh, Lucas, \& Smith, 1999; Diener, 2000, 2006), involving judgments based on individual life experiences (Diener, 2006; Extremera \& Fernández-Berrocal, 2014). Thus, the study of motivation in the elderly population is very important (Vallerand, O'Connor, \& Hamel, 1995): (i) this process makes it possible to understand the factors that regulate behaviour in older people; (ii) the changes associated with ageing involve the perception of incompetence, or feelings that reduce self-determination of behaviour; (iii) the understanding of motivation is necessary to understand the psychological process of ageing and the factors that influence health at this stage of life and; (iv) finally, because their understanding allows structuring contexts, where they interact, in order to promote more selfdetermined behaviours and, consequently, a greater perception of well-being in subjects' lives.

Besides, concerning the assessment of BPN fulfilment, the authors proposed that they should be evaluated not just 
globally but also in specific contexts. In this way the Basic Need Satisfaction General Scale (BNSG-S: Gagné, 2003), developed from the measurement scale of the fulfilment of BPN in the work context (BNSW-S: Ilardi, Leone, Kasser, \& Ryan, 1993), appears to be an instrument that allows the assessment of the fulfilment of BPN in subjects' general life. However, Johnston and Finney (2010) criticized, for the first time, the way in which the ability to assess BPN fulfilment through the BNSG-S (i.e., three factors, 21 items). Nevertheless, in this study, the author resorted to the scale to obtain a global value of BPN fulfilment without any analysis of the psychometric properties of the scale.

Thus, Johnston and Finney (2010) analysed the scale's factorial structure by testing several models and concluded that the model with a factorial structure consisting of three factors and 16 items (autonomy: three items; competence: six items; relatedness: seven items) was the only one that presented a good fit. Thus, it was necessary to include the associated method effect on the negative items so that the model could adjust to the data (Johnston \& Finney, 2010). According to Gonzále-Cutre, Sierra, Cervelló, Esteve-Salar, and Alonso-Álvarez (2015), the method effect associated with these items indicates that they share a common variance that is not explained by or related to the latent variables, but simply, linked to the fact that the items are written in a negative form.

In Portugal, Sousa, Pais-Ribeiro, Palmeira, Teixeira, and Silva (2012) adapted the original version (BNSG-S; Gagné, 2003) to the Portuguese language through an exploratory factorial analysis conducted in two independent samples. Results showed in both groups, the presence of three factors, with satisfactory internal consistency values (i.e., >.70) in the dimension of relationship and unsatisfactory (i.e., <.70) in the dimension of autonomy and competence. In both groups, the authors also verified the unidimensionality of the scale, and its internal consistency was appropriate.

Despite the weaknesses, found Sousa et al. (2012) assumed the original model (three factors, 21 items), sustaining this decision with Rotter's (1990) affirmation, according to whom statistical methods are useful tools but do not replace the theory. Regardless of this decision, Sousa et al. (2012) emphasized the fact that the model has the potential to be depurated further.

Thus, in addition to the study by Sousa et al. (2012), which was developed in a Portuguese population through two groups that included elderly subjects, the mean age of a group of $39.99 \pm 11.89$ years old and $35.05 \pm 11.91$ years old, indicates that the vast majority of subjects are under 60 years old, thus making the validation of the scale in this population relevant. Furthermore, in order not to weaken the study method, it is essential to confirm the initial structure of the scale in order to ensure that the instrument used is valid and reliable for the population in question.

Therefore, studies with older people indicate that the assessment of life's quality is affected by the health condition, and well-being can be influenced by other factors (e.g., mate- rial conditions, social and familiar relations, social roles) that are usually modified by age, and can be a protective element in health, reducing the risk of chronic diseases and promoting longevity (Steptoe, Deaton, \& Stone, 2015).

Thus, considering the demographic projections for the next decades which show an overall aging of the population (European Commission, 2018), and that the satisfaction of $\mathrm{BPN}$ has a significant and positive effect on well-being, (Moutão, Alves, Monteiro, \& Cid, 2015) it is intended, after the validation of the Portuguese version of BNSG-S (Sousa et al., 2012) in a sample the Portuguese elderly people trough confirmatory factor analyses, verify, trough structural equation model, the effect of the global perception of BPN satisfaction in subjective well-being variables: life satisfaction; positive affect and negative affect.

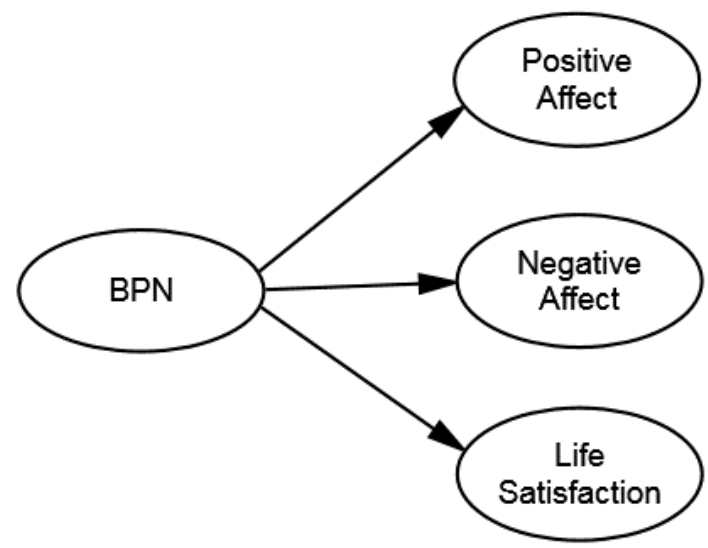

Figure 1. Hypothesized Causal Model.

\section{Method}

\section{Participants}

For validation of the BNSG-S, we used a sample with 311 subjects (244 females, 67 male) of Portuguese nationality, who were students of senior colleges and day centres and were aged between 60 and 90 years $(M=68.59$; $D P=6.60)$. For the second part of this study, it was used a sample $(\mathrm{n}=300)$ including 238 females and 62 males, aged between 60 and 90 years old $(M=68.59 ; D P=6.54)$.

\section{Instruments}

For the present study, the Portuguese version (Sousa et al., 2012) of the Basic Need General Satisfaction Scale (BNSG-S: Gagné, 2003) was used. This questionnaire is constituted by 21 items, to which the subjects respond on a seven-point "Likert" scale ranging between one ("totally disagree") to seven ("totally agree"). The items are grouped into three factors (autonomy: seven items; competence: six items; relatedness: eight items). The score is generated by the items' summation, having previously carried out the inversion of the negative items. 
The Portuguese version of Positive and Negative Affect Schedule (PANAS: Watson, Clark, \& Tellegen, 1988), validated in the elderly population by Antunes et al. (2019), was used for assessment of positive affect and negative affect in this population. The Portuguese of the Satisfaction with Life Scale (SWLS: Diener, Emmons, Larsen, \& Griffin, 1985), validated in elderly people by Antunes et al. (2019) was used, for assessment satisfaction with life.

\section{Data collection}

The data were collected in similar locations and conditions for all the elements, guaranteeing a focused environment during the completion of the questionnaire. It can also be noted that all the participants took part voluntarily, with guaranteed anonymity and confidentiality of the data collected.

\section{Statistical analysis}

We used structural equation models (SEM), which involve a multivariate technique that allows users to simultaneously examine relationships between latent constructs and measurement variables, such as between several construct models (Hair, Black, Babin, \& Anderson, 2014).

In operational terms, SEM was made in AMOS 21 software, underlying the guidelines from several authors (Byrne, 2010; Hair et al., 2014; Worthington \& Whittaker, 2006). We used the maximum likelihood (ML) estimation method through an $x$-squared $\left(\chi^{2}\right)$ test with the respective degrees of freedom (df) and significance level (p). Additionally, we also used the following indexes of adjustment quality: Standardized Root Mean Square Residual (SRMR), Comparative Fit Index (CFI), Tucker-Lewis Index (TLI), Root Mean Square Error of Approximation (RMSEA) and the respective confidence interval $(90 \% \mathrm{CI})$. In the current study, we adopted the cut-off values that $\mathrm{Hu}$ and Bentler (1999) suggested: SRMR $\leq .08$, CFI e TLI $\geq .95$ e RMSEA $\leq .06$. However, we also took the advice from several authors (e.g., Byrne, 2010; Hair et al., 2014; Marsh, Hau, \& Wen, 2004), and considered values equal or higher than .90 in case of incremental indexes and between $\leq .05$ and $\leq .08$ in absolute indexes, to avoid the rejection of good models. The theory underlying the ML (maximum likelihood) estimation method assumes data have a normal multivariate distribution, which is necessary to analyse Mardia's coefficient (see Mardia, 1970). According to Byrne (2010), a normalized Mardia's coefficient higher than 5.0 indicates that the data does not have a normal multivariate distribution. Therefore, we used the Bollen-Stine bootstrap for a sample of 2,000 as a protection measure (Nevitt \& Hancock, 2001). Our inspection of the data revealed no missing values.

We examined the convergent validity to verify how the items relate to the respective factor by calculating the average variance extracted (VEM), considering values for such a VEM $\geq .05$. We also assessed the discriminant validity (DV), which checks whether the factors are sufficiently distinct from the others, a situation that occurs when the value of the VEM of each factor is greater than the square of the relation between the respective factors. We also analysed the composite reliability (CR), which also allows the evaluation of the internal consistency of the factors, taking $\mathrm{CR} \geq .70$ as the cut-off, as suggested by Hair et al. (2014).

\section{Results}

As we can see in table 1, only the Model 3 (three factors/11 items), which showed an adjustment to the data. We also conducted an analysis of the hierarchical model, and this presented a very satisfactory data adjustment.

Table 1. Indices of the tested models' adjustment.

\begin{tabular}{lcccccccc}
\hline Models & $\chi^{2}$ & $\mathrm{df}$ & $\mathrm{B}-\mathrm{S}$ & SRMR & TLI & CFI & RMSEA \\
\hline Model 1 & 1047.67 & 186 & $<.01$ & .15 & .45 & .51 & .13 & .09 \\
Model 2 & 170.49 & 51 & $<.01$ & .06 & .84 & .88 & .09 \\
Model 3 & 103.16 & 41 & $<.01$ & .05 & .90 & .93 & .07 & .07 \\
Hierarchical Model & 104.48 & 42 & $<.01$ & .05 & .90 & .93 & .07 & $.05-.08$ \\
\hline
\end{tabular}

Note. $\chi^{2}=$ chi-square; $\mathrm{df}=$ degrees of freedom; B-S=Bollen-Stine Bootstrap; SRMR=standardized root mean square residual; TLI=Tucker-Lewis index; $\mathrm{CFI}=$ comparative fit index; RMSEA=root mean squared error of approximation; 90\% CI=RMSEA value confidence interval. Model 1 (21 items); Model 2 (12 items); Model 3 (11 items).

In figure 2, we can observe the existence of positive correlations between all BPN: Autonomy-Competence $(r=.76)$, Autonomy-Relation ( $r=.71)$ Competence-Relation $(r=.91)$.

From the analysis of Table 2, we can see that the measurement model shows internal consistency values for the autonomy (.68) and relatedness (.77) factors because the composite reliability values are around the recommended value (.70). Nevertheless, weaknesses were observed at the level of internal consistency in the competence factor, since the composite reliability value is .58. Relative to the convergent validity, the results indicate weaknesses in this point of discussion in all the factors, since the VEM values are lower than the value commonly recommended (VEM $\geq$ $.50)$. 


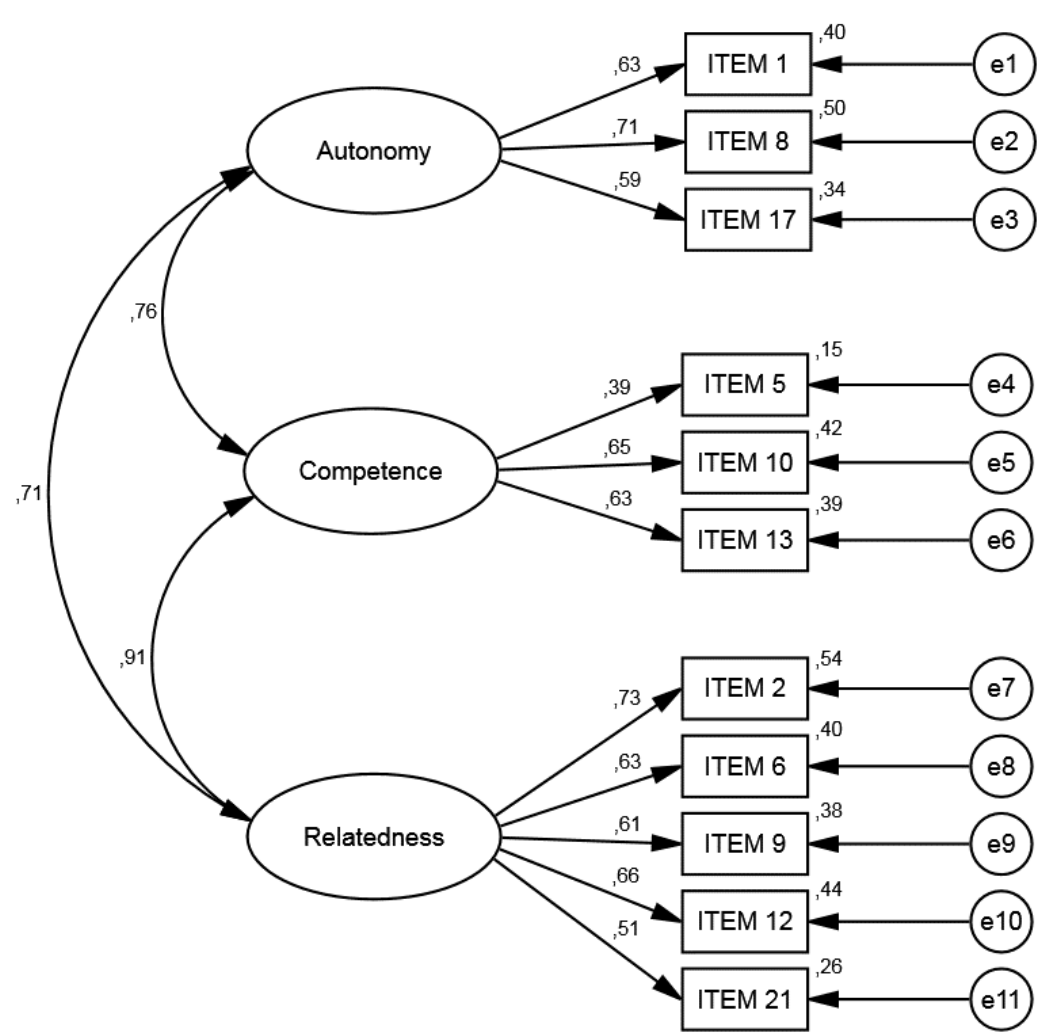

Figure 2. Standardized individual parameters of the final model of the BNSG-S (3 factors/11 items)

Table 2. Composite reliability and convergent and discriminant validity.

\begin{tabular}{lcccc}
\hline Items & CR & VEM & 1 & 2 \\
\hline 1. Autonomy & .68 & .41 & - & \\
2. Competence & .58 & .32 & $.58^{*}$ & - \\
3. Relatedness & .77 & .40 & $.50^{*}$ & $.82^{*}$ \\
\hline
\end{tabular}

Note. Composite reliability (CR); average variance extracted (VEM); * correlation squared $\left(\mathrm{r}^{2}\right)$.
Regarding the hypothetical model studied, we verified a satisfactory adjustment to the data, because the cut-off values adopted were respected for the absolute and incremental indexes.

Table 3. Adjustment indexes of the tested models

\begin{tabular}{lcccccccc}
\hline Models & $\chi^{2}$ & $d f$ & B-S & CFI & TLI & SRMR & RMSEA & $90 \%$ CI \\
\hline Model 1 & 288,469 & 132 & .000 & .912 & .908 & .083 & .063 & $.053-.073$ \\
Autonomy & 283,091 & 132 & .001 & .908 & .894 & .076 & .062 & $.072-.024$ \\
Competence & 262.588 & 132 & .003 & .918 & .905 & .075 & .058 & $.068-.105$ \\
Relatedness & 334.442 & 167 & .001 & .909 & .896 & .079 & .058 & $.067-.070$ \\
\hline
\end{tabular}

Note. $\chi^{2}=$ chi-square; $\mathrm{df}=$ degrees of freedom; B-S= Bollen-Stine bootstrap; SRMR $=$ Standardized Root Mean Square Residual; TLI $=$ Tucker-Lewis Index; CFI = Comparative Fit Index; RMSEA = Root Mean Squared Error of Approximation; 90\% CI = Confidence Interval of the value from RMSEA.

By the analysis of the effect of BPN total satisfaction in the life of Portuguese elderly individuals on the studied subjective well-being, we verified, as shown in Figure 3, that positive and significant effects exist between BPN satisfaction, positive affect $(B=.53)$ and life satisfaction $(B=.53)$. Also, in other hand, there is a positive effect between BPN and negative affect $(\beta=.01)$ that was not significant.

We also analyzed models that reflect the relation of each BPN individually and subjective well-being variables. In this way, for the BPN of autonomy, it was verified a positive and significant effect on life satisfaction $(\beta=.49)$ and positive affect $(\beta=.60)$ and a not significant negative effect on negative affect $(\beta=-.05)$; on the other hand, the BPN of competence obtained a direct and significant effect on life satisfaction $(\beta=.62)$ positive affect $(\beta=.51)$ and a not significant negative effect on negative affect $(\beta=-.11)$. At last, relatively to the BPN of relatedness, we also verified a direct and positive effect with life satisfaction $(\beta=.50)$ and positive affect $(\beta=.23)$, and a non-significant effect on negative affect $(\beta=.02)$. 


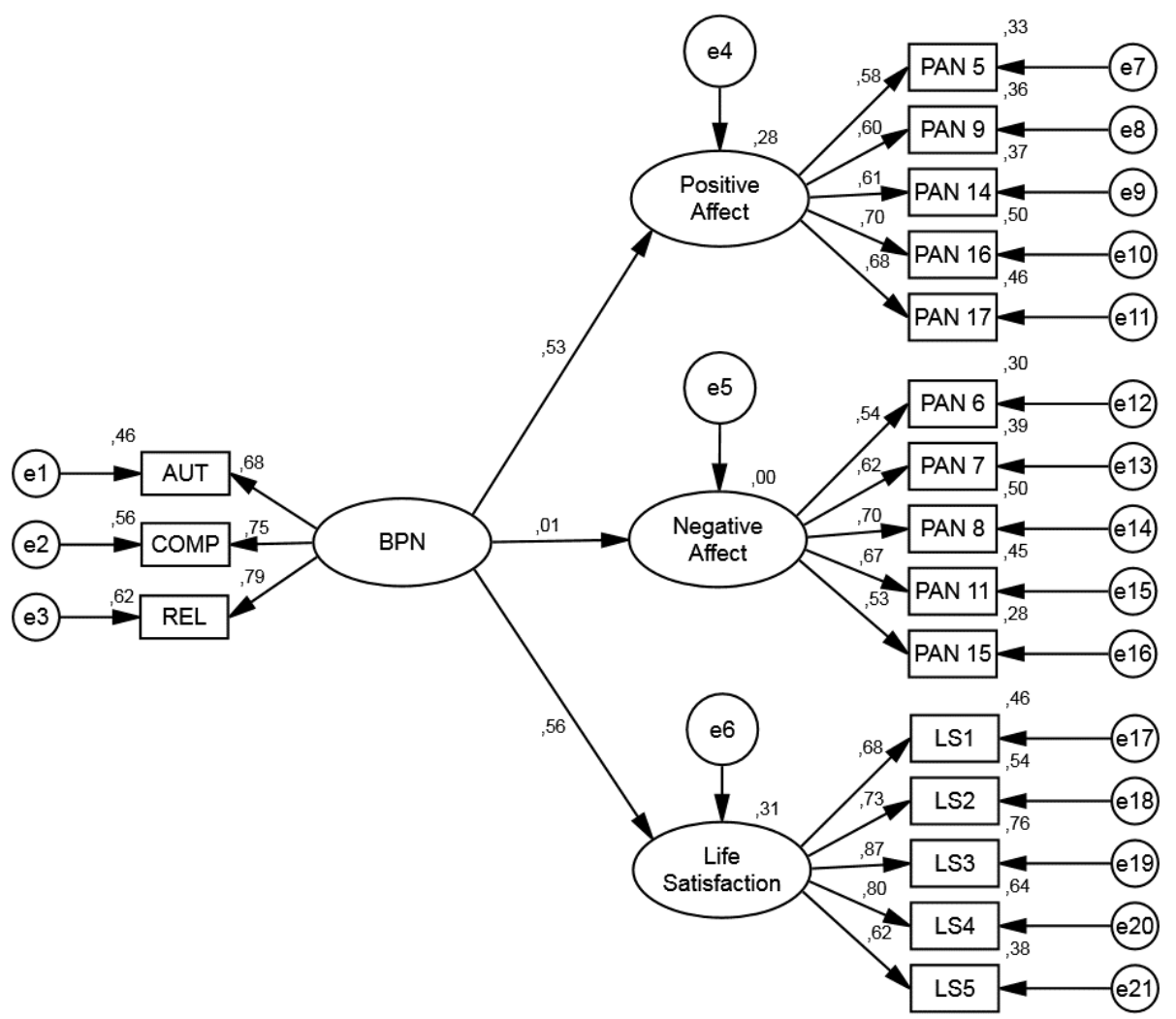

Figure 3. Individual parameters standardized from the model.

\section{Discussion}

Taking into consideration the first goal of this study, the validation of the Portuguese version of the BNSG-S (Sousa et al., 2012) in a sample of Portuguese older people, we proceeded, through a confirmatory factorial analysis, to study the psychometric qualities of the scale.

In the first instance, we found a lack of adjustment of the initial model to the data (Model 1 - three factors/21 items), as the cut-off values adopted in $\mathrm{Hu}$ and Bentler's (1999) methodology were not reached. In the presence of this evidence, we tried to understand which parameters were contributing to the model's non-adjustment, and we verified that all the negative items $(3,4,7,11,15,18,18,20)$ showed a very low factorial weight in the respective factors, so they can be interpreted (<.30) (Hair et al., 2014). Furthermore, many of these items showed cross-loadings with other factors (i.e., item 18 between the relatedness and the autonomy factor).

Consequently, we decided to analyse the model without the inclusion of these items (Model 2 - three factors/12 items), having revealed the non-adjustment again. Despite improvements in the analysed indices, the cut-off values of $\mathrm{Hu}$ and Bentler (1999) were not achieved.

The non-adjustment of the second model led us, like the analysis of the results of the first model, to analyse its potential weaknesses. Therefore, we verified that item 14 ("The people with whom I am familiar, every day, usually take into account my feelings ... I totally disagree - I totally agree") has cross-loading with the relatedness factor. Indeed, when analysing the semantic form of the item, we noticed that the beginning of the sentence suggests the subject's relationship with others: "The people with whom I am familiar with, every day ...".

Accordingly, a third model appeared (three factors/11 items), without the negative items and item 14. Through the results obtained by confirmatory factorial analysis, we verified the fit of the model to the data.

Therefore, we identified an identical model to the one suggested by Johnston and Finney (2010), but without the presence of the five negative items that the model included, which led to a bigger reduction, from our perspective correcting the model and eliminating the perturbation caused by the negative items.

The negative items disturb the factorial structure of theoretical models since they give rise to a new factor when it is not theoretically expected or justified (Ye, 2009). From the respondents' point of view, according to some authors (e.g., Moraes \& Primi, 2002), questionnaires with negative items, require more attention and understanding by the subjects, which may explain the distinction of variability between the positive and the negative items, because, instead of presenting a clear answer, they appear as denial (Gouveia, Mendes, Soares, Monteiro, \& Santos, 2015).

Regarding the reliability of the scale, we performed a 
composite reliability analysis, since it is a technique that solves the limitations associated with Cronbach's $\alpha$ (Hair et al., 2014). The composite reliability values found ( $\mathrm{CR}_{\text {Autonomy }}$ .68; $\mathrm{CR}_{\text {Competence }} .58$; $\mathrm{CR}_{\text {Relation }} .77$ ) demonstrate the reliability of the scale limitations, specifically for the competence factor, since the indicator value for this factor is below the cutoff value of .70. However, due to the importance of retaining factors with at least three items, we accepted the competence factor in this way.

Hair et al. (2014) asserted that it is also important in the construct analysis to study convergent and discriminant validity. The results show that the value of the VEM is below the cut-off value of .50 for all the factors. Convergent validity relates how the items in a particular construct must converge or share a high proportion of the common variance, which may be measured by the factorial weight of the items and the VEM (Hair et al., 2014). Through the VEM, we confirmed that this type of validity is not obtained, but when we examined the factorial weights, we verified that these limitations are fainter. The indications that the factor weights should be $\geq .50$, ideally more than $\geq .70$, are satisfied, because almost all the items, except item 5 , have a factor weight $\leq .50$. However, the average value of the VEM, below the cut-off value, means that each factor does not contribute strongly to the explained variance of the answers of the respective items, the average variance of the error being bigger than the average variance extracted.

The discriminant validity, which is accepted when the VEM value for each construct is greater than the correlation's square between this construct and another (Fornell \& Larcker, 1981; Hair et al., 2014), also remains unconfirmed, since the value obtained is bigger than the VEM of each factor. This confirms that the factors are not distinct but have strong correlations with each other, and this is normal when studying a theoretical construct with these features. However, when the correlations between factors are above .50 , the existence of a second-order factor is very likely (Kahn, 2006). In fact, several studies on the assessment of the fulfilment of BPN in various contexts, support the presence of a model with three first-order factors and a second-order factor (Gagné, 2003; Moutão, Cid, Alves, Leitão, \& Vlachopoulos, 2012; Ntoumanis, 2005; Vlachopoulos, 2007).

The data revealed, also, that the hierarchical model of fulfilment of BPN fit the data quite well, having obtained values very close to those of Model 3, which reinforced the scale's ability to measure the satisfaction of the BPN, either through the three factors or due to the GSI in this population. From this model results a significant factorial weight of .76 between the GSI and the autonomy factor and quite a satisfactory weight of .94 and .96 between the GSI and the competence and relatedness factors, respectively. Besides the factorial weight of autonomy factor being quite satisfactory, the values of the factorial weights obtained in the competence and relatedness factors are indicative values of a welldefined structure (Hair et al., 2014; Kahn, 2006). The results obtained also show a very acceptable value of composite re- liability in the second-order factor $(\mathrm{CR}=.92)$, for which the GSI explains $77 \%$ of the average variance of the three BPN.

We verified that the correlation results between the factors are positive: autonomy-competence $(r=.76)$, autonomyrelatedness $(r=.71)$, and competence-relatedness $(r=.91)$. This situation becomes interesting when compared with other studies that investigated the satisfaction of the BPN because in general, the correlations between the autonomy and the competence factor reach values between $(\mathrm{r}=.67)$ and $(\mathrm{r}=82)$; the relatedness and competence factors between $(\mathrm{r}=.43)$ and $(\mathrm{r}=.78)$; and the relatedness and autonomy factors between $(\mathrm{r}=.61)$ and $(\mathrm{r}=.81)$ (Conroy \& Coatsworth, 2007; Gagné, 2003; Johnston \& Finney, 2010; Meyer, Enström, Harstveit, Bowles, \& Beevers, 2007; Vlachopoulos \& Michailidou, 2006; Wey, Shaffer, Young, \& Zakalik, 2005). There seems to be, in a generalized way, higher correlation values between the autonomy and the competence factor, which means that the more competent the subject's behaviour is perceived to be, the more autonomous this feels. On the other hand, the satisfaction of the relatedness need appears to have less influence on competence need fulfilment. However, in our study, the correlation between these two factors (i.e., relatedness-competence) shows the highest value (i.e., $r=.96)$, a situation that allows us to suggest that older people may feel more competent when they can establish interpersonal relationships, which underlines the importance of the social context in this area. These data support the opinion of Wills (1996), who affirmed that older people's competence cannot be considered without taking into account the environment in which they are located.

After the validation of the BNSG-S, we analysed the effect of BPN satisfaction on subjective well-being in olders adults through the structural equation model. The results indicate that BPN satisfaction in the overall life of the Portuguese elderly population has a positive effect on life satisfaction and positive affect. In the other way, no there is a significant effect between BPN and the negative affect.

Consequently, the results obtained, corroborate the research carried out overtime on this theme. Vallerand, O'Connor, \& Blais (1989) found that the elderly perceived greater satisfaction with life in nursing homes, where they promoted more self-determined behaviour in their daily lives. In relation to affects, Reis, Sheldon, Gable, Roscoe, \& Ryan (2000) verified that greater perception of BPN satisfaction, also determines, among other variables, a positive change in positive affects for this population. More recently, Molix and Nichols (2013) have confirmed in a general way, among other results, a positive association between BPN satisfaction and the subjective well-being of the elderly.

In addition to the fact that the overall satisfaction of $\mathrm{BPN}$ has a positive direct effect on well-being variables, it was also verified that each BPN when studied in a separated way, has a positive direct effect with life satisfaction and a positive affect, and a negative effect, also in the three BPN, with negative affect.

In fact, all the BPN (i.e., autonomy, competence, rela- 
tion) have a prevalent role in promoting subjective wellbeing. However, it was verified that the BPN of competence and autonomy were those that demonstrated a higher effect on the studied well-being variables. Couto et al. (2017) also verified that competence is the BPN that performance the highest effect on elderly subjective well-being, by the influence of this need on happiness. The need of competence (i.e., the subject ability of be effective in the interaction with the enveloping) has a central role for the subjective wellbeing in this population, once, according to Neto, Lima, Gomes, Santos, and Tolentino (2012), is understood as the capacity that the subject has in resorting to compensatory activities. Thus, according to Neubauer, Schiling, and Wahl (2017) as the subject perceives a decrease in the BPN of competence in their daily lives, this try to be involved in activities in which they can perceive a greater satisfaction of this BPN, even affirming, according to autonomy necessities (i.e., ability to regulate their own actions), that their satisfaction is closely related to the need for competence, because the perception of autonomy requires that the need of competence was satisfied. To point out, the importance of the need for a relationship because the strong relationship between this and the need for competence reinforces the idea that involvement has a decisive role in the perception of the satisfaction of the competence need and consequently for the well-being of the elderly.

\section{Conclusions}

Given the results obtained, we can confirm that Model 3 (three factors/11 items: autonomy, three items; competence,

\section{References}

Antunes, R., Couto, N., Vitorino, A., Monteiro, D., Moutão, J., Marinho, D., \& Cid, L. (2019). Atividade física e satisfação com a vida dos idosos: contributos para a validação da Satisfaction With Life Scale (SWLS) na população portuguesa. Revista Iberoamericana de Psicologia del Ejercicio y el Deporte, 14(1): 24-27.

Antunes, R., Couto, N., Vitorino, A., Monteiro, D., Marinho, D., \& Cid, L. (2019). "Physical activity and affect of the elderly: Contribution to the validation of the Positive and Negative Affect Shedule (PANAS) in the Portuguese population". Journal of Human Sport and Exercise, 15(2). http://dx.doi.org/10.14198/jhse.2020.152.08.

Byrne, B. (2010). Structural Equation Modeling with AMOS. Basic Concepts, Applications, and Programming (2nd ed.). New York, NY: Taylor \& Francis Group.

Conroy, D., \& Coatsworth, J. (2007). Assessing autonomy-supportive coaching strategies in youth sport. Psychology of Sport \& Exercise, 8(5), 671-684. http://dx.doi.org/10.1016/j.psychsport.2006.12.001.

Couto, N., Antunes, R., Monteiro, D., Moutão, J., Marinho, D., \& Cid, L. (2017). Impact of the Basic Psychological Needs in Subjective Happiness, Subjective Vitality and Physical Activity in an Elderly Portuguese Population. Motricidade, 13(2), https://dx.doi.org/10.6063/motricidade.9746.

Deci, E., Koestner, R., \& Ryan, R. (1999). A meta-analytic review of experiments examining the effects of extrinsic rewards on intrinsic motivation. Psychological Bulletin, 125, 627-668.

Deci, E., \& Ryan, R. (2000). The "what" and "why" of goal pursuits: Human needs and the self-determination of behavior. Psychological Inquiry, 11(4), 227-268. three items; relatedness, five items), measuring the Portuguese version of the BNSG-S, has acceptable psychometric qualities, providing assurance of the assessment of the BPN satisfaction in the overall life of Portuguese older people, either for the first-order model or the second-order model.

Therefore, we can say that the BNSG-S Model 3 allows the assessment of BPN fulfilment through the three factors separately or as a global index of psychological need fulfilment, equally, in this population. However, because of the weaknesses associated with the competence factor, relating to item five 5 (i.e., "The people whom I know tell me that I am good in what I do ..."), and the lacking verification of convergent validity, we advocate, the continued study of the psychometric qualities of the BNSG-S to achieve a more refined measure of fulfilment assessment of the BPN, not only in the senior population but in all social positions of the population, suggesting the semantic reformulation of item 5 , because we believe that its construction is detrimental to the proper assessment of the BPN competence.

It is also concluded that the BPN have a direct and positive effect on the well-being studied variables, proving, once again, their importance for the subjective well-being of the elderly population. This data reinforces the need to promote BPN by all those who are part of these subjects' life so that we can contribute to a better quality of life for the elderly.

Funding information: This work was supported by national funds through the Portuguese Foundation for Science and Technology, I.P., under the project UID04045/2020.

Deci, E., \& Ryan, R. (2008). Self-determination theory: A macrotheory of human motivation, development, and health. Canadian Psychology, 49(3), 182-185. http://dx.doi.org/10.1037/a0012801.

Diener, E. (2000). Subjective well-being. The science of happiness and a proposal for a national index. The American Psychologist, 55(1), 34-43.

Diener, E. (2006). Guidelines for national indicators of subjective well-being and ill-being. Applied Research in Quality of Life, 1, 151-157.

Diener, E., \& Chan, M. (2011). Happy People Live Longer: Subjective WellBeing Contributesto Health and Longevity. Applied Psychology: Health and Well-Being, 3(1), 1-43.http://dx.doi.org/10.1111/j.17580854.2010.01045.x.

Diener, E., Emmons, R., Larsen, R., \& Griffin, S. (1985). The Satisfaction With Life Scale. Journal of Personality Assessment, 49, 71-75.

Diener, E., Suh, E., Lucas, R., \& Smith, H. (1999). Subjective well-being: Three decades of progress. Psychological Bulletin, 125, 276-302.

European Commission (2018). The 2018 Ageing Report. Underlying Assumptions and Projection Methodologies. Retrieved from https://ec.europa.eu/info/sites/info/files/economyfinance/ip065_en.pdf.

Extremera, N., \& Fernandéz-Berrocal, P. (2014). The Subjective Happiness Scale: translation and preliminary psychometric evaluation of a Spanish version. Social Indicators Research, 119(1), 473-481. http://dx.doi.org/10.1007/s11205-013-0497-2.

Fornell, C., \& Larcker, D. F. (1981). Evaluating structural equation models with unobservable variables and measurement error. Journal of Marketing Research, 18(1), 39-50. http://dx.doi.org/10.2307/3151312. 
Gagné, M. (2003). The role of autonomy support and autonomy orientation in prosocial behavior engagement. Motivation and Emotion, 27, 199-223. http://dx.doi.org/10.1023/A:1025007614869.

Gonzále-Cutre, D., Sierra, A., Cervelló, E., Esteve-Salar, J., \& AlonsoÁlvarez, J. (2015). Evaluación de las propriedades psicométricas de la Escala de Satisfacción de las BPN en General com adultos espanñoles. Terapia Psicológica, 33(2), 81-92.

Gouveia, V., Mendes, L., Soares, A., Monteiro, R., \& Santos, L. (2015). Escala de Necessidade de Cognição (NCS-18): Efeitos de Itens Negativos em Sua Estrutura Fatorial. Psicologia Reflexão e Crítica, 28(3), 425-433. http://dx.doi.org/10.1590/1678-7153.201528301.

Hair, J., Black, W., Babin, B., \& Anderson, R. (2014). Multivariate data analysis (7th ed.). Harlow: Pearson Educational, Inc.

Hu, L., \& Bentler, P. (1999). Cut off criteria for fit indexes in covariance structure analysis: Conventional criteria versus new alternatives. Structural Equation Modeling, 6(1), 1-55. http://dx.doi.org/10.1080/10705519909540118.

Ilardi, B., Leone, D., Kasser, R., \& Ryan, R. (1993). Employee and supervisor ratings of motivation: Main effects and discrepancies associated with job satisfaction and adjustment in a factory setting. Journal of Applied Social Psychology, 23, 1789-1805. http://dx.doi.org/10.1177/0146167201278002.

Johnston, M., \& Finney, S. (2010). Measuring basic needs satisfaction: Evaluating previous research and conducting new psychometric evaluations of the Basic Needs Satisfaction in General Scale. Contemporary Educational Psychology, 280-296. http://dx.doi.org/10.1016/j.cedpsych.2010.04.003.

Kahn, J. (2006). Factor analysis in counseling psychology. Research, training, and practice: Principles, advances and applications. The Counseling Psychologist, $34(5)$

684-718. http://dx.doi.org/10.1177/0011000006286347.

Mardia, K. (1970). Measures of multivariate skewness and kurtosis with applications. Biometrika, 57(3), 519-530.

Marsh, H., Hau, K., \& Wen, Z. (2004). In search of golden rules: Comment on hypothesistesting approaches to setting cutoff values for fit indexes and dangers in overgeneralizing Hu and Bentler's (1999) findings. Structural Equation Modeling, 11(3), 320-341. http://dx.doi.org/10.1207/s15328007sem1103_2.

Meyer, B., Enström, M., Harstveit, M., Bowles, D., \& Beevers, C. (2007). Happiness and despair on the catwalk: Need satisfaction, well-being, and personality adjustment among fashion models. Journal of Positive Psychology, 2(1), 2-17. http://dx.doi.org/10.1080/17439760601076635.

Molix, L. \& Nichols, C. (2013). Satisfaction of basic psychological needs as a mediator of the relationship between community esteem and wellbeing. International Journal of Wellbeing, 3(1), 20-34. http://dx.doi.org/10.5502/ijw.v3i1.2

Moraes, I., \& Primi, R. (2002). Escala de avaliação de tipos psicológicos: validade e precisão. Psico-USF, 7(1), 25-34.

Moutão, J., Alves, S., Monteiro, D., \& Cid, L. (2015). O papel de mediação das necessidades psicológicas na associação entre o suporte de autonomia e o bem-estar psicológico em praticantes de fitness. Motricidade,11(2), 29-40. https://doi.org/10.6063/motricidade.3734.

Moutão, J., Cid, L., Alves, J., Leitão, J., \& Vlachopoulos, S. (2012). Validation of the Basic Psychological Needs in Exercise Scale in Portuguese sample. Spanish Journal of Psychology, 15 (1), 399-409. http://dx.doi.org/10.5209/rev_SJOP.2012.v15.n1.37346.

Neto, J., Lima, C., Gomes, Santos, M., \& Tolentino, F. (2012). SWB em idosos praticantes de atividade física. Motricidade, 8(2), 1097-1104.

Nevitt, J., \& Hancock, G. (2001). Performance of bootstrapping approaches to model test statistics and parameter standard error estimation in structural equation modeling. Structural Equation Modeling, 8, 353-377. http://dx.doi.org/10.1207/S15328007SEM0803_2.

Neubauer, A., Schilling, O., \& Wahl, H. (2017); What Do We Need at the End of Life? Competence, but not Autonomy, Predicts Intraindividual Fluctuations in Subjective Well-Being in Very Old Age, The Journals of
Gerontology: $\quad$ Series $\quad B, \quad 72 \quad$ (3), 425-435. https://doi.org/10.1093/geronb/gbv052

Ntoumanis, N. (2005). A prospective study of participation in optional school physical education using a self-determination theory framework. Journal of Educational Psychology, 97(3), 444-453. http://dx.doi.org/10.1037/0022-0663.97.3.444.

Reis, H., Sheldon, K., Gable, S., Roscoe, R., \& Ryan. R. (2000). Daily wellbeing: The role of autonomy, competence, and relatedness. Personality and Social Psychology Bulletin, 26(4), 419-435. http://dx.doi.org/ 10.1177/0146167200266002.

Ryan, R., \& Deci, E. (2000a). Self-Determination Theory and the Facilitation of Intrinsic Motivation, Social Development, and Well-Being. American Psychologist, 55(1), 68-78.

Ryan, R., \& Deci, E. (2000b). Intrinsic and extrinsic motivations: Classic definitions and new directions. Contemporary Educational Psychology, 25, 54-67. http://dx.doi.org/10.1006/ceps.1999.1020.

Ryan, R., \& Deci, E. (2002). An overview of self-determination theory. In E. Deci \& R. Ryan (Eds.), Handbook of self-determination research (pp. 333). Rochester, NY: The University of Rochester Press.

Ryan, R., \& Deci, E. (2007). Active human nature: Self-determination theory and the promotion and maintenance of sport, exercise and health. In M. Hagger \& N. Chatzisarantis (Eds.), Intrinsic motivation and selfdetermination in exercise and sport (pp. 1-19). Champaign, IL: Human Kinetics.

Rotter, J. (1990). Internal versus external control of reinforcement: A case history of a variable. American Psychologist, 45, 489-493. http://dx.doi.org/10.1037/0003-066x.45.4.489.

Sousa, S., Pais-Ribeiro, J., Palmeira, A., Teixeira, P., \& Silva, M. (2012). Estudo da Basic Need Satisfaction in general Scale para a língua portuguesa. Psicologia, Saúde e Doenças, 13(2), 209-219.

Steptoe, A., Deaton, A., \& Stone, A. (2015). Psychological wellbeing, health and ageing. Lancet, 385(9968), 640-648. http://dx.doi.org/10.1016/S0140-6736(13)61489-0.

Vallerand, R., \& O'Connor, B., \& Blais, M. (1989). Life Satisfaction of Elderly Individuals in Regular Community Housing, in Low-Cost Community Housing, and High and Low Self-Determination Nursing Homes. The International Journal of Aging and Human Development, 28(4). https://doi.org/10.2190/JQ0K-D0GG-WLQV-QMBN

Vallerand, R., O'Connor, B., \& Hamel, M. (1995). Motivation in later life: Theory and assessment. The International Journal of Aging \& Human Development, 41(3), 221-238. https://doi.org/10.2190/YLFM-DGUEHRL2-VWLG

Vlachopoulos, S. (2007). Psychometric evaluation of the Basic Psychological Needs in Exercise Scale in community exercise programs: A crossvalidation approach. Hellenic Journal of Psychology, 4, 52-74.

Vlachopoulos, S., \& Michailidou, S. (2006). Development and initial validation of a measure of autonomy, competence, and relatedness in exercise: The Basic Psychological Needs in Exercise Scale. Measurement in Physical Education and Exercise Science, 10(3), 179-201.

Watson, D., Clark, L., \& Tellegen, A. (1988). Development and validation of brief measures of positive and negative affect: The PANAS scale. Journal of Personality and Social Psychology, 54, 1063-1070. http:/ / dx.doi.org/10.1037/0022-3514.54.6.1063

Wei, M., Shaffer, P., Young, S., \& Zakalik, R. (2005). Adult Attachment, Shame, Depression, and Loneliness: The Mediation Role of Basic Psychological Needs Satisfaction. Journal of Counseling Psychology, 52(4), 591601. http://dx.doi.org/10.1037/0022-0167.52.4.591.

Wills, S. (1996). Everyday cognitive competence in elderly persons: Conceptual issues and empirical findings. The Gerontologist, 36(5), 595-601.

Worthington, R., \& Whittaker, T. (2006). Scale Development Research: A Content Analysis and Recommendations for Best Practices. The Counseling Psychologist, 34(6), 806-838. https://doi.org/10.1177/0011000006288127

Ye, S. (2009). Factor structure of the General Health Questionnaire (GHQ12): The role of wording effects. Personality and Individual Differences, 46, 197-201. http://dx.doi.org/10.1016/j.paid.2008.09.027. 